\title{
The European gas market: the effects of liberalization on retail prices
}

\author{
G. Capece ${ }^{1}$, F. Di Pillo ${ }^{1}$, M. Gastaldi ${ }^{2} \&$ N. Levialdi ${ }^{1}$ \\ ${ }^{I}$ Department of Enterprise Engineering, University of Rome \\ "Tor Vergata", Rome, Italy \\ ${ }^{2}$ Department of Electrical and Information Engineering, \\ University of L'Aquila, Italy
}

\begin{abstract}
This paper aims to analyse the effects deriving from the liberalization process in Europe following Directive 98/30/EC. More specifically, the objective is to analyse the competitiveness in the retail market. In order to do so, it is necessary to begin by observing the average retail prices established by various European retail operators, and their differences regarding the two categories of consumers (domestic and industrial). The cost of imported natural gas plays an important role in the determination of the retail price. Thus we investigate the relationship between the retail and import price, and the changes in this relationship due to the liberalization process.

Keywords: gas market liberalization, natural gas retail prices, natural gas import prices, linear regression analysis.
\end{abstract}

\section{Introduction}

The liberalization of the gas market in Europe began due to the first gas directive (Directive 98/30/EC) [1], which established common rules regarding the storage, transmission, supply and distribution of natural gas.

This paper aims to investigate the effects on the retail market stemming from the European liberalization process.

The retail price of a service offered by firms competing in interconnected networks depends on several factors such as the production, transport and distribution costs, which directly affect the retail price of natural gas. The 
analysis of transport prices by Cremer and Laffont [2] represents a benchmark model of gas transportation pricing from an industrial-economic perspective.

This paper focuses on the relationship between the distribution and production segments. In the context of the European supply market structure the analysis of this relationship is especially important. Production in the EU in particular is primarily characterised by the fact that the natural gas does not originate from domestic sources, with the exception of producers such as Norway, the UK and the Netherlands.

Since natural gas is largely imported into the EU, it is interesting to analyse the effects that import prices have on retail prices and also to examine how these effects have varied as a consequence of the liberalization process.

A similar analysis, which solely considered the Spanish market, was made by Garcia [3] and focused on the deregulation process carried out by the Spanish government elected in 1996, whereby competition was introduced into the natural gas sector for the first time. In Weir's paper [4] regarding the British natural gas market, he discusses the forces, which led to the deregulation of the U.K. gas supply industry.

In this paper we consider the European situation and compare the differing levels of competition from one country to the next before and after liberalisation in the natural gas retail segment.

We begin by examining the average retail prices established by sales operators and how these vary with regard to the two categories of consumers (domestic and industrial) and to geographical position. Subsequently we study the relationship between the import price and the average prices paid by both the domestic and industrial retail consumers, by means of a regression analysis.

The regression analysis is performed regarding two time periods: firstly a pre-liberalization period from 1992 to 1997, followed by a post-liberalization period from 1998 to 2006.

This paper is organized as follows: Section 2 describes the gas market liberalization process in Europe. Section 3 shows the trends in the retail prices of several different European countries and of different consumer categories. Section 4 provides the regression analysis regarding household consumers. Section 5 presents the regression analysis as regards industrial consumers. Section 6 concludes.

\section{The liberalization process in Europe}

The liberalization process of the gas market in Europe began in the early 1990s and ended in 2003 with the Gas Directive 2003/55/EC [5], which is the European gas legislation in force at the present.

The first step towards opening the market to competition was the implementation of Directive 90/377/EC [6], which aimed to make gas prices more transparent. This law was followed by Directive 91/296/EEC [7], which was intended to make the energy trade between the various European States more efficient. 
The liberalization of the industry was brought about by the first gas directive (Directive 98/30/EC) [1], which established common rules on the transmission, storage, supply and distribution of natural gas.

The architecture of the first gas directive was developed on two levels: firstly it ensured that all the member states must abide by the fundamental principles of the European Directive, and secondly it recognized that every member State should have the full authority to decide upon the timescale and the means by which such principles would be upheld. Moreover, this directive allowed the member States to maintain, modify or choose the regulatory systems, which were most appropriate to the particular circumstances of their own nation.

During the pre-liberalization period, many of the European natural gas markets were characterized by the presence of enforced or effective monopolies, both in the transport and retail sectors. The Directive, in order to create competitive conditions in several national markets, utilised a mechanism founded upon two main concepts: the market opening and the eligible customers. Market opening is intended to mean a market which is open to competition and thus is founded upon the principle of the consumer's freedom of choice. As regards the second mechanism, the eligible customers are a category of customers who have the right to acquire gas at a competitive price from the supplier. Under the terms of the Directive any consumers who used more than 25 million cubic metres/year were immediately granted the right to choose their supplier.

In 2003 the EU issued Gas Directive 2003/55/EC [5] which is the basis of the existing legislative framework. Although this mainly reiterated the former directive and retained the same structure, some points were modified and some articles, which had previously been outlined in more general terms, were defined in greater detail. The most recent market reform states that as from July 2007 all consumers will be free to choose their gas supplier. The market for larger consumers was opened several years before [8].

Moreover, the European Gas directive requires the obligatory unbundling of transport and trading: i.e. all gas operators belonging to the member states have to separate their gas transportation and trading functions into separate companies.

A further key aspect of the directive is the Regulated TPA (Third Party Access): potential network users must be able to request and obtain access to gas facilities under transparent, objective and non-discriminatory conditions.

The means of implementation and the time schedule with which the EU25 members have adopted the directive vary widely. Some NRA (National Regulatory Authorities) have not only met, but have also completed the schedule established by the EU ahead of time, whereas others seem not to have complied with scheduled conditions and risk exceeding the deadlines.

As regards the opening of the natural gas retail market, in September 2005 full liberalization was completed in Denmark, Germany, Spain, Italy, the Netherlands, Austria and the United Kingdom. In other States, such as Belgium, the Czech Republic, France, Ireland, Luxembourg, Hungary and Poland, the 
freedom to choose a supplier is still limited to non-household customers (in theory households are due to be able to choose their retailers as from July 2007).

In many European countries a high number of gas retailers operate in the market [9]. In reality, a considerable number of these retail suppliers mask the fact that few retailers are of any significant size (above a threshold of 5\% market share). In fact a high number of retailers does not necessarily reflect a sizable degree of competition in the country. It should be noted that in many European countries, aside from the degree of concentration, the gas retailing market is split into a number of regional distributors where the consumer does not have a real choice of a supplier.

A significant indicator of the degree of the market competition is the number of consumers who switch from one gas supplier to another. This switching from the incumbent operator to other operators indicates that the final consumer may benefit from alternative suppliers on the market.

It can be clearly seen from a survey carried out by NRA that in many European countries where switching is possible, gas consumers are reluctant to exercise their right to change supplier. Often alternative offers are not available, or are too similar to represent a real choice. The presence of incumbent operators with strong market power and insufficient unbundling, especially when found at the distribution level, causes foreclosure in the industry and represents an obstacle to switching.

It should be stated that the switching rate is only low for household consumers, whereas it is relatively high for the industrial consumers. The low switching rate for household consumers is dependent on several factors. Firstly, changing suppliers is often perceived as risky by families that are loyal to their own incumbent local supplier. Also household consumers frequently have incomplete information regarding the opportunities that liberalization presents. Moreover, household consumers believe that the discounts offered by the alternative suppliers are too low and are afraid that the quality of the service will be worse as a consequence. Finally, there is also a considerable lack of alternative suppliers.

\section{Gas price trends}

In order to understand the trends of prices paid by the final consumers of natural gas, we use the data provided by Eurostat [10]. In particular, we consider the D3 category of domestic consumers and the I3-1 category of industrial consumers. All prices are expressed in euros in real terms from January 1992, year of the signing of the Maastricht Treaty, to December 2006.

For the purposes of this study we shall consider the principle European countries which were the first member states of the European community: Belgium, France, Germany, Italy, the Netherlands and Spain. Since the main aim of this paper is to analyse the relationship between retail and import prices, we have excluded the United Kingdom due to the fact that their indigenous supplies allowed them to remain a net exporter of gas until 2004. 
Conversely, we shall examine the Netherlands which, in spite of also being a net exporter, does have a significant rate of gas import; in 2003 gas imported into the Netherlands totalled about $26 \%$.

Figures 1 and 2 show the trends of household and industrial gas prices respectively. Since traditionally the price of gas has always been indexed and adjusted in relation to the price of crude oil, the main variations seen here are linked to variations in crude oil price trends. The Netherlands have the lowest average prices both regarding household and industrial consumers. In contrast, the highest average prices are found in Italy for both categories, in Spain regarding only household consumers, and in Germany and Belgium where industrial consumers are concerned.

Between January 1992 and January 1999, a relatively stable trend can be observed for household consumers in Belgium, France, Germany and the Netherlands (fig. 1), whereas there was some slight variation in the trends of Italy and Spain. From January 1999 to January 2001 the average retail price paid by household consumers increased significantly. From 2001 there was a downward trend until 2004, with the Netherlands being the only exception.

Between January 2004 and December 2006, the great increase in the IPE BRENT crude oil price caused gas retail prices to rise steeply. With regard to household consumers between 2004 and 2006 the highest price increases occurred in Germany and France, where retail prices rose by more than $20 \%$. The smallest price increases occurred in Italy and Spain.

It should be noted that the industrial prices are lower than the household prices due to the higher level of consumption in the industrial category.

As shown in figure 2, gas prices were relatively stable for industrial consumers until January 1999 (except for the Netherlands), and there is a similar trend in the prices paid by household consumers.

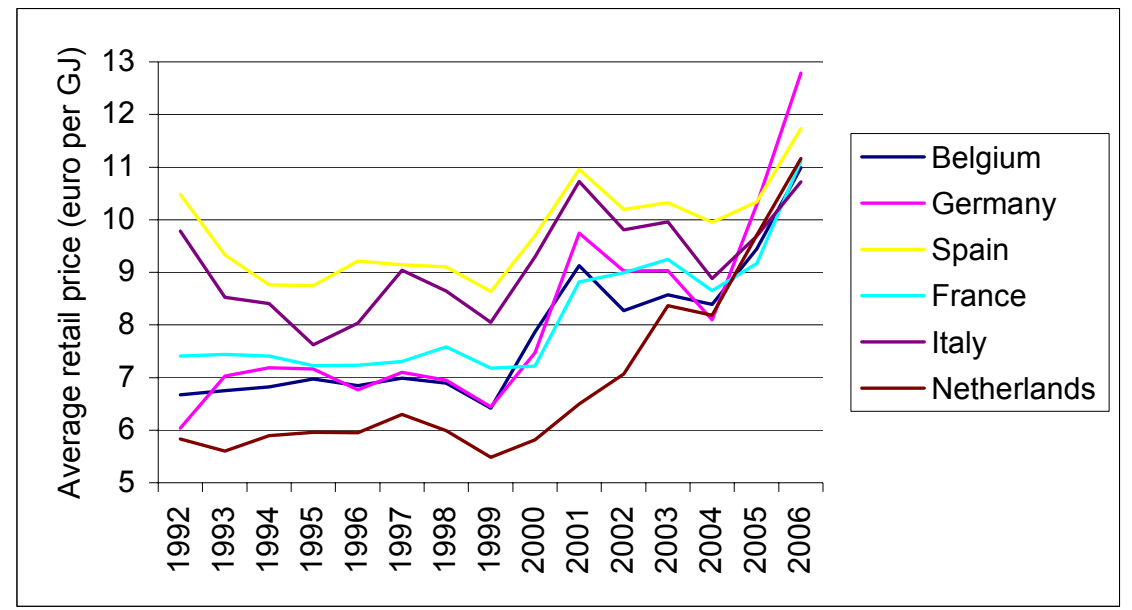

Figure 1: Gas prices for household consumers (standard consumer D3) from January 1992 to December 2006. 


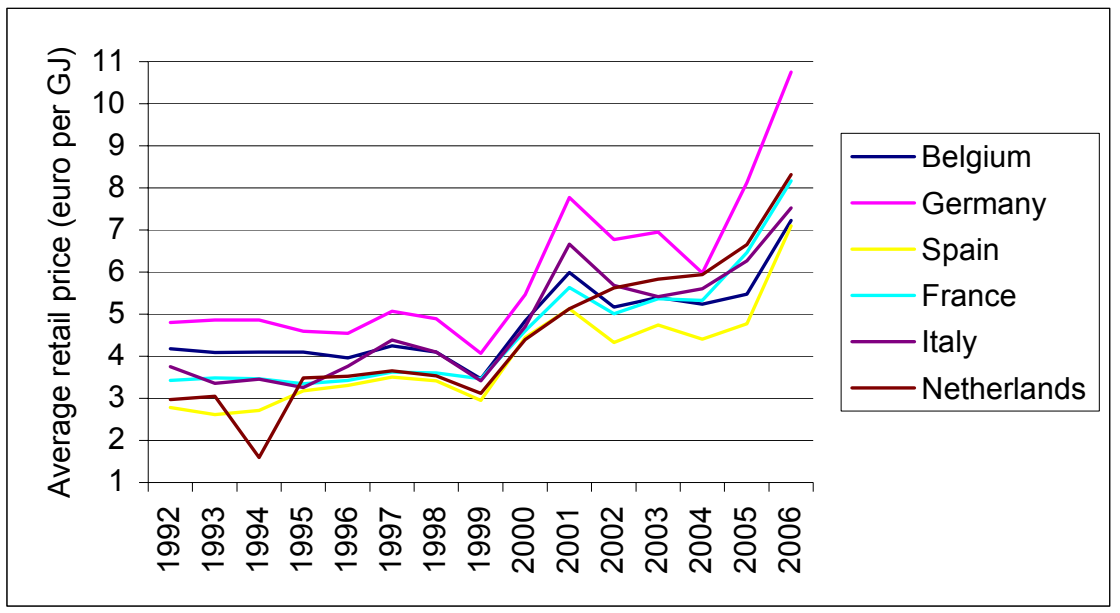

Figure 2: $\quad$ Gas prices for industrial consumers (standard consumer I3-1) from January 1992 to December 2006.

\section{Regression analysis for household consumers}

In this section, we consider the target market of household consumers, in particular the D3 category with an annual consumption of 83.7 GJ (standard consumer).

A regression analysis over two time periods is carried out: the first from 1992 to 1997 (pre-liberalization), and the second from 1998 to 2006 (post liberalization). The aim of this study is to analyse the effects deriving from the opening process of the gas retail market. More specifically, we investigate the relationship between the natural gas retail and import prices and the changes of this relationship due to the liberalization process.

The natural gas import prices have been provided by Eurostat in euros in real terms [10].

The linear regression is calculated using the Ordinary Least Squares (OLS) method with a confidence level of $95 \%$. We hypothesise that the yearly differences in the natural gas consumer prices (dependent variable) are dependent on the natural gas import prices (independent variable).

When the two time periods are compared from tables 1 and 2, in the post liberalization phase there is a noticeable increase of the $R$-squared values $\left(R^{2}\right)$ which rises steeply to reach higher levels, with the exception of the Netherlands. We can therefore affirm with a $95 \%$ confidence level that over the post liberalization period the yearly variations of the natural gas import prices are significant enough to explain the yearly variations of the natural gas prices paid by household consumers.

A plausible explanation for this result is that it is due to the legislative framework adopted by the NRA after the European directive 98/30/CE [1] which applied a policy of ceiling prices for natural gas. This practice tends to reduce the 
existing margin between the average price paid by domestic consumers and the average import price paid by retailers.

Table 1: $\quad$ Linear regression for the 1992-1997 period.

\begin{tabular}{|l|c|c|c|c|c|}
\hline Countries & $\mathrm{R}^{2}$ & $\begin{array}{c}\text { Regression } \\
\text { coefficient }\end{array}$ & $\begin{array}{c}\text { Standard error of } \\
\text { regression coefficient }\end{array}$ & Intercept & $\begin{array}{c}\text { Standard error } \\
\text { of intercept }\end{array}$ \\
\hline Belgium & 0.196 & 0.359 & 0.364 & 6.036 & 0.818 \\
\hline France & 0.008 & -0.056 & 0.309 & 7.459 & 0.694 \\
\hline Germany & 0.046 & 0.622 & 1.413 & 5.488 & 3.170 \\
\hline Italy & 0.078 & 1.401 & 2.402 & 5.429 & 5.391 \\
\hline Netherlands & 0.380 & 0.910 & 0.588 & 3.884 & 1.319 \\
\hline Spain & 0.001 & -0.142 & 2.084 & 9.596 & 4.677 \\
\hline
\end{tabular}

Table 2: $\quad$ Linear regression for the 1998-2006 period.

\begin{tabular}{|l|c|c|c|c|c|}
\hline Countries & $\mathrm{R}^{2}$ & $\begin{array}{c}\text { Regression } \\
\text { coefficient }\end{array}$ & $\begin{array}{c}\text { Standard error of } \\
\text { regression coefficient }\end{array}$ & Intercept & $\begin{array}{c}\text { Standard error } \\
\text { of intercept }\end{array}$ \\
\hline Belgium & 0.859 & 1.515 & 0.232 & 3.338 & 0.803 \\
\hline France & 0.668 & 1.213 & 0.323 & 4.579 & 1.118 \\
\hline Germany & 0.746 & 2.021 & 0.445 & 2.066 & 1.539 \\
\hline Italy & 0.830 & 0.994 & 0.169 & 6.181 & 0.587 \\
\hline Netherlands & 0.512 & 1.660 & 0.613 & 1.995 & 2.118 \\
\hline Spain & 0.900 & 1.055 & 0.133 & 6.551 & 0.459 \\
\hline
\end{tabular}

By comparing the data from the two tables, it is possible to analyse the increase of the R-squared values in the post liberalization phase. The greatest increases are observed in Germany, Spain, France and Italy. The last three countries have a similar regulatory structure: domestic gas prices are regulated by the NRA and thus tariffs are determined by using an algorithm which includes all costs deriving from import, infrastructure (storage, transport and distribution) and wholesale trading. Although until 2004 Germany still did not have a specific regulatory authority, gas prices were governed in a more general way by the German Energy Regulator, which was a section of the Telecommunications Regulator.

In these four countries, the increase in R-squared values is caused by the regulation of retail prices which is intended to determine a cost-reflective price, and thus to reduce the margin between the average prices paid by household consumers and the average price of imported natural gas.

Belgium follows the countries above with a smaller increase. The Belgian natural gas market is characterized by a regulatory system which is divided between federal and local regulatory bodies.

The three Belgian regions (Flanders, Wallonia and Brussels) each govern liberalization policy and distribution in their individual areas, whilst transmission, LNG and storage are regulated at a federal level by the Commission de Régulation de l'Electricité et du Gaz (CREG). The liberalization process was different in each of the three Belgian regions, which is why the 
regulation in Belgium was not homogeneous and could be one of the reasons for the lesser increase of the R-squared values.

The Netherlands shows the smallest increase which may be due to their supply structure. The country is a net gas exporter on account of their significant indigenous reserves, although a considerable percentage of the gas supply is imported. This means that in the post liberalization phase the connection between the retail price and the import cost is weaker than in the other countries.

\section{Regression analysis for industrial consumers}

The target market in this section is the industrial consumers, in particular the I31 category with an annual consumption of 41,860 GJ with a maximum daily offtake of 209 GJ and a maximum hourly off-take of 26 GJ (standard consumer).

Again in this case, a regression analysis is carried out over the same two time periods: the first from 1992 to 1997 (pre-liberalization), and the second from 1998 to 2006 (post liberalization).

As in the previous section, the natural gas import prices have been provided by Eurostat in euros in real terms, excluding taxes [10].

The same methodology of linear regression is used with a confidence level of $95 \%$. We hypothesise that the yearly differences in the natural gas industrial consumer prices (dependent variable) are dependent on the natural gas import prices (independent variable).

Also in this case, the R-squared values of all the countries increase in the post liberalization period.

It should be noted that retail prices for industrial consumers are not regulated and hence the high R-squared values, occurring in the post liberalization phase for all countries, stem from the greater effective competition between retail operators that reduce their margins with respect to the import costs. In spite of the absence of retail price regulation, free competition has resulted in a greater dependency between the retail prices and the cost of import.

In the post liberalization phase, the R-squared values are all greater than 0.75 which means that the linear relationship estimated using the regression curve, is a good indicator of the relationship between the independent variable (average import price) and the dependent variable (average retail price).

Table 3: $\quad$ Linear regression for the 1992-1997 period.

\begin{tabular}{|l|c|c|c|c|c|}
\hline Countries & $\mathrm{R}^{2}$ & $\begin{array}{c}\text { Regression } \\
\text { coefficient }\end{array}$ & $\begin{array}{c}\text { Standard error of } \\
\text { regression coefficient }\end{array}$ & Intercept & $\begin{array}{c}\text { Standard error } \\
\text { of intercept }\end{array}$ \\
\hline Belgium & 0.289 & 0.331 & 0.260 & 3.371 & 0.582 \\
\hline France & 0.771 & 1.516 & 0.312 & 0.189 & 1.080 \\
\hline Germany & 0.444 & 0.850 & 0.476 & 2.885 & 1.068 \\
\hline Italy & 0.678 & 2.210 & -0.760 & -1.286 & 1.707 \\
\hline Netherlands & 0.091 & 2.614 & 2.134 & -2.810 & 4.790 \\
\hline Spain & 0.350 & 1.400 & 0.956 & -0.120 & 2.146 \\
\hline
\end{tabular}


Table 4: $\quad$ Linear regression for the 1998-2006 period.

\begin{tabular}{|l|c|c|c|c|c|}
\hline Countries & $\mathrm{R}^{2}$ & $\begin{array}{c}\text { Regression } \\
\text { coefficient }\end{array}$ & $\begin{array}{c}\text { Standard error of } \\
\text { regression coefficient }\end{array}$ & Intercept & $\begin{array}{c}\text { Standard error } \\
\text { of intercept }\end{array}$ \\
\hline Belgium & 0.883 & 1.211 & 0.166 & 1.135 & 0.575 \\
\hline France & 0.781 & 0.533 & 0.141 & 2.271 & 0.317 \\
\hline Germany & 0.768 & 2.102 & 0.437 & -0.323 & 1.510 \\
\hline Italy & 0.920 & 0.540 & 0.570 & 1.470 & 0.164 \\
\hline Netherlands & 0.760 & 1.670 & 0.360 & -0.225 & 1.240 \\
\hline Spain & 0.756 & 1.215 & 0.902 & 1.215 & 0.261 \\
\hline
\end{tabular}

\section{Conclusions}

The liberalization process of the gas market in Europe began following the first gas directive in 1998 (Directive 98/30/EC), which established common rules on the transmission, storage, supply and distribution of natural gas, and ended in 2003 with the Gas Directive 2003/55/EC, which is the European gas legislation in force at the present.

This paper aimed to analyse the effects of the liberalization process in the European natural gas market which was carried out by the NRA and the legislative decrees that were intended to open the natural gas markets in all European States.

For this reason, in the first part of this paper, we studied the trends of retail consumer prices of natural gas. In particular, we considered the D3 category of domestic consumers and the I3-1 category of industrial consumers.

Moreover, we carried out a regression analysis by considering two time periods: the first (pre-liberalization) from 1992 to 1997 and the second (post liberalization) from 1998 to 2006. The aim of this study was to analyse the effects deriving from the process of the opening of the retail gas market. More specifically, we investigated the relationship between the retail and import prices of natural gas and the changes in this relationship due to the liberalization process.

The R-squared values increased both for the domestic and the industrial consumers. It should therefore be noted that whether or not there was regulation after the gas market liberalization, a greater dependency between the import cost and the retail price was observed. This also implies that in the post liberalization phase there is greater effective competition between the retail operators that have consequently reduced their import cost margins.

\section{Acknowledgement}

This work was supported by MIUR funds PRIN 2005 (n. 2005098172). 


\section{References}

[1] European parliament and council Directive 98/30/EC of 22 June 1998 concerning common rules for the internal market in natural gas.

[2] Cremer H. and Laffont J-J., Competition in gas Market, European Economic Review, 46, pp. 928-935, 2002.

[3] Garcia L.A.R., The liberalization in the Spanish gas market, Energy Policy, 34, pp. 1630-1644, 2005.

[4] Weir C., Regulation and the Development of Competition in the U.K. Gas Supply Industry, Review of Industrial Organization, 15, pp. 135-147, 1999.

[5] European parliament and council Directive 2003/55/EC of 26 June 2003 concerning common rules for the internal market in natural gas and repealing Directive 98/30/EC.

[6] European parliament and council Directive 90/377/EC of 29 June 1990 concerning a Community procedure to improve the transparency of gas transparency of gas and electricity prices charged to industrial end-users.

[7] Council Directive 91/296/EEC of 31 May 1991 on the transit of natural gas through grids.

[8] EUROSTAT, European Gas Market Indicators of the liberalization process 2004-2005, available: http://epp.eurostat.ec.europa.eu.

[9] EUROSTAT, Competition Indicators in the Gas Market of the European Union, available: http://epp.eurostat.ec.europa.eu.

[10] EUROSTAT, Environment and energy, Energy Statistics-prices, Gasdomestic and industrial consumers-yearly prices, available: http://epp.eurostat.ec.europa.eu 